\title{
Instituições e a Informalidade no Mercado de Trabalho ${ }^{\star}$
}

\author{
- GABRIEL UlySSEA*
}

\begin{abstract}
RESUMO
O objetivo deste artigo é desenvolver um modelo que concilie os principais aspectos institucionais relativos à informalidade no mercado de trabalho. Trata-se de um modelo de matching com dois setores, formal e informal, que incorpora os principais tradeoffs que firmas e trabalhadores enfrentam ao decidir em que setor ingressar. $O$ modelo apresenta uma inovação que o torna mais coerente aos principais fatos estilizados e às evidências empíricas mais recentes. Os resultados das simulações de políticas mostram que elevações no seguro-desemprego e reduções no imposto sobre a folha geram impactos positivos, porém reduzidos, sobre os principais indicadores do mercado de trabalho. Ao contrário, uma intensificação da fiscalização governamental leva a significativas reduções da informalidade, mas também provoca uma elevação substancial da taxa de desemprego e uma piora em outros indicadores do mercado de trabalho brasileiro.
\end{abstract}

\section{Palavras-Chave}

setor informal, instituições, mercado de trabalho

\begin{abstract}
This paper aims to develop a model capable of reconciling some of the main institutional aspects relative to labor market informality. It is a two-sector, formal and informal, matching model that incorporates the main tradeoffs faced by workers and firms when deciding in which sector they will operate. The model presents an innovation that makes it more coherent with most stylized facts and recent empirical evidence. Policy simulation's results show that increasing unemployment benefits and reducing payroll taxes generate positive, although small effects over labor market indicators. However, intensifying government audition rates implies a substantial reduction of informality rates, but it also causes unemployment to increase and the deterioration of other important indicators in the Brazilian labor market.
\end{abstract}

\section{KEYWORDS}

informal sector, institutions, labor market

Jel Classification

J4I, 017

+ O autor é extremamente grato a José Márcio Camargo e Ricardo Paes de Barros pela orientação, comentários e críticas. O autor agradece também a valiosa participação de Carlos Tomei e os comentários de Gustavo Gonzaga, Maurício Cortez Reis, João Pedro Azevedo e Miguel Foguel. Por fim, o autor agradece as críticas e sugestões de dois pareceristas anônimos. Os erros remanescentes são de inteira responsabilidade do autor.

* Instituto de Pesquisa Econômica Aplicada (IPEA). Endereço para contato: Av. Presidente Antonio Carlos, 5I, I4 andar. Rio de Janeiro, RJ. E-mail: ulyssea@ipea.gov.br.

(Recebido em dezembro de 2005. Aceito para publicação em agosto de 2007). 


\section{$1 \quad$ INTRODUÇÃO}

Sob uma ótica estritamente econômica, os principais custos e benefícios para firmas e trabalhadores associados aos setores formal e informal estão direta ou indiretamente ligados às instituições. No caso das firmas, é possível classificar os custos da formalidade em dois grandes grupos: os custos de entrar no setor formal, relacionados ao custo de legalização e registro do empreendimento; e os custos de permanecer no setor, que podem ser divididos em duas categorias - custos monetários (impostos e taxas) e custos burocráticos.

Já os custos da informalidade resumem-se a dois tipos: as penalidades impostas à firma quando a infração é detectada; ${ }^{1}$ e a incapacidade das firmas informais de se beneficiarem parcial ou integralmente dos bens ofertados pelo governo, entre os quais o sistema judicial e a polícia. Este segundo aspecto tem como conseqüência a impossibilidade de as firmas exercerem plenamente o direito de propriedade sobre seus produtos e capital, o que aumenta a incerteza e os custos de transação e monitoramento dos negócios informais. Além disso, a incapacidade de assegurar os direitos de propriedade faz com que estas firmas tenham seu acesso ao mercado de crédito severamente prejudicado, afetando, assim, sua capacidade de desenvolvimento (LOAYZA, 1996).

Do ponto de vista dos trabalhadores, o principal custo da formalidade está associado aos impostos inerentes ao contrato formal, em particular o imposto de renda e a contribuição previdenciária. Por outro lado, a informalidade implica a perda dos benefícios associados ao emprego formal - seguro-desemprego, férias remuneradas, entre outros. Além disso, o setor informal caracteriza-se por apresentar taxas de separação e rotatividade mais elevadas do que aquelas observadas no setor formal e, portanto, maior instabilidade das relações de trabalho.

Estes diferentes aspectos relativos à informalidade no mercado de trabalho têm sido tratados de forma predominantemente isolada na literatura. ${ }^{2}$ Mais recentemente, contudo, alguns trabalhos vêm tentando conciliar vários dos aspectos institucionais relativos ao mercado de trabalho em geral, enfatizando as interações entre as decisões de firmas e trabalhadores no mesmo. Dentre estes destaca-se o trabalho de Acemoglu (2001), que desenvolve um modelo simples de matching com dois setores que mostra como as instituições do mercado de trabalho podem ter impactos de primeira ordem

1 Ainda que a fiscalização por parte do Estado não seja efetiva a ponto de tornar proibitiva a atividade e a contratação ilegal de mão-de-obra, estas penalidades representam um peso considerável para as firmas, especialmente no caso dos pequenos empreendimentos. Além disso, muitas vezes as firmas são obrigadas a pagar propinas aos agentes de fiscalização para poderem continuar a exercer suas atividades ou simplesmente decidem mantê-las em uma escala reduzida para evitar a fiscalização governamental.

2 Ver Ulyssea (2006) para uma discussão mais detalhada. 
sobre o nível e a composição do emprego. ${ }^{3}$ No caso específico da informalidade, Cavalcanti (2001), Bouev (2005) e Boeri e Garibaldi (2005) ( na lista final a data é 2006) analisam os efeitos da legislação trabalhista sobre a composição do emprego em uma economia que possui um setor informal que não está sujeito à regulação governamental. De forma semelhante, Fugazza e Jacques (2004) desenvolvem um modelo de mercado de trabalho dual à Saint-Paul (1996) com uma estrutura de matching e busca direcionada por parte dos trabalhadores.

O modelo desenvolvido aqui é construído a partir do trabalho de Acemoglu (2001) e é semelhante em espírito a Cavalcanti (2001), Fugazza e Jacques (2004), Bouev (2005) e Boeri e Garibaldi (2005). Trata-se de um modelo de matching com dois setores - formal e informal - que considera explicitamente algumas das principais instituições do mercado de trabalho (custos de admissão/demissão, imposto sobre a folha, seguro-desemprego, entre outros). De acordo com o que é usualmente feito na literatura, a presente análise concentra-se nos equilíbrios de steady state do modelo e, portanto, diz respeito aos efeitos de mudanças institucionais sobre o equilíbrio de longo prazo do mercado de trabalho.

Não obstante as semelhanças com os trabalhos anteriores, o modelo apresenta uma inovação em sua estrutura de matching que o torna mais adequado para a análise da informalidade no mercado de trabalho. De maneira geral, as duas estruturas tradicionalmente consideradas para os modelos setoriais de busca e matching são busca direcionada (mercados separados) e busca não-direcionada (mercados unificados). $\mathrm{O}$ que se faz aqui é uma combinação destas duas abordagens. Ainda que existam dois mercados separados - pois cada setor possui funções de matching e tensões ( $t i$ ghtness) particulares - é feita a hipótese de que a busca por parte dos trabalhadores é não-direcionada, ou seja, estes procuram empregos nos setores formal e informal sem nenhuma distinção.

Esta estrutura apresenta algumas vantagens importantes em relação aos trabalhos anteriores, em particular: as condições de oferta e demanda por trabalho em um determinado setor afetam diretamente as decisões de firmas e trabalhadores no outro setor; não é preciso supor que os trabalhadores direcionam sua busca para apenas um tipo de emprego; mantém-se uma riqueza analítica maior ao tratar os mercados formal e informal separadamente; e evita-se a existência de taxas de desemprego distintas para os setores formal e informal. Esta estrutura também confere maior flexibilidade ao modelo, o que parece se adequar melhor às evidências empíricas mais recentes relativas à informalidade no mercado de trabalho brasileiro.

3 É importante ressaltar que o foco da análise de Acemoglu (2001) não é exatamente a informalidade no mercado de trabalho. O autor considera uma economia em que existem dois setores, o de "bons" empregos e o de "maus" empregos. Não obstante, a analogia com a dualidade formal-informal é imediata. 
Além disso, a partir do modelo construído é possível realizar uma série de exercícios de simulação para avaliar quantitativamente os impactos de determinadas instituições sobre o mercado de trabalho brasileiro. Neste trabalho, são analisados os impactos de mudanças em três aspectos institucionais distintos: o valor do seguro-desemprego; a intensidade da fiscalização governamental sobre o setor informal; e o imposto sobre a folha de salários. Estas políticas são interessantes por se situarem em pólos distintos no leque de possíveis intervenções relativas à questão da informalidade. Em um extremo, o seguro-desemprego representa uma política de incentivo à formalidade e, no outro, a fiscalização governamental constitui uma política de repressão à informalidade. Sendo assim, analisar o grau de efetividade e os impactos gerais sobre o mercado de trabalho destas políticas pode contribuir para a definição do tipo de intervenção mais adequada para lidar com esta questão.

Alguns trabalhos existentes na literatura sugerem que o sistema brasileiro de segurodesemprego pode ter efeitos adversos significativos sobre o desempenho do mercado de trabalho (ver, por exemplo, BARROS et al., 2001). Contudo, as simulações realizadas aqui indicam o contrário: uma elevação substancial no seguro-desemprego produziria um pequeno aumento no grau de formalização e uma ligeira redução no grau de informalidade e na taxa de desemprego. Como conseqüência, tanto a produtividade média quanto o produto total teriam um pequeno aumento em relação ao status quo da economia. Não obstante, trata-se de uma política pouco efetiva, uma vez que seria necessário dobrar o valor atual do benefício para alcançar um aumento de um ponto percentual no grau de formalização do mercado de trabalho. Da mesma forma, reduções na alíquota de imposto sobre a folha teriam efeitos limitados sobre a composição do emprego e sobre o desemprego.

Quanto à intensificação da fiscalização governamental, esta é com frequiência apontada como uma política potencialmente adequada para reduzir o grau de informalidade. Se adotada, esta política implicaria manter o arcabouço institucional existente no mercado de trabalho brasileiro e simplesmente aumentar a efetividade (enforcement) das instituições existentes via uma fiscalização mais intensa por parte do governo. De fato, os exercícios realizados aqui indicam que esta é uma política extremamente efetiva para reduzir a informalidade. Contudo, seus efeitos sobre o desempenho do mercado de trabalho são bastante negativos, provocando uma forte elevação na taxa de desemprego e, conseqüentemente, uma redução do produto total da economia.

O restante do trabalho está estruturado da seguinte forma: a Seção 2 apresenta e discute em detalhes o modelo; a Seção 3 apresenta os exercícios de simulação e discute os resultados observados no mercado de trabalho brasileiro; finalmente, a Seção 4 apresenta as considerações finais. 


\subsection{A Economia}

Há apenas dois tipos de bens nesta economia, o de consumo e o intermediário. $\mathrm{O}$ mesmo bem intermediário pode ser produzido tanto no setor formal quanto no informal. Já o bem de consumo final é produzido por uma única firma representativa que utiliza uma tecnologia com retornos constantes de escala representada aqui por uma função CES dos dois bens intermediários:

$$
Y=\left(a Y_{F}^{\rho}+(1-a) Y_{I}^{\rho}\right)^{\frac{1}{\rho}}
$$

$Y_{F}$ e $Y_{I}$ representam a produção agregada do bem intermediário produzido nos setores formal e informal, respectivamente. $\mathrm{O}$ parâmetro $0<a<1$ mede a importância relativa do produto agregado formal na produção de $Y$ e o parâmetro $\rho$ determina a elasticidade de substituição entre $Y_{F}$ e $Y_{I}$, dada por $1 /(1-\rho)$. As preferências de todos os agentes estão definidas apenas sobre o bem final, cujo preço é normalizado à unidade. $\mathrm{O}$ único fator utilizado na produção dos bens intermediários é o trabalho, e quando ocorre um casamento entre uma firma de um determinado setor e um trabalhador, uma unidade do respectivo bem é produzida. Há um contínuo de trabalhadores e firmas, ambos homogêneos, neutros ao risco e com medida l. A taxa de desconto de trabalhadores e firmas é dada por $r$. O tempo é contínuo no modelo.

Uma das principais características que diferenciam um posto de trabalho formal de um informal é o seu custo fixo de criação. Para criar um emprego formal a firma deve incorrer em um custo de criação $K_{F}$, enquanto para criar um emprego informal o custo é dado por $K_{I}, \operatorname{com} K_{F}>K_{I}$. Esta hipótese é motivada a partir de aspectos institucionais que caracterizam a maior parte dos países em desenvolvimento: abrir uma vaga no setor formal é mais caro devido aos elevados custos dos trâmites burocráticos envolvidos no registro da firma (que seriam custos à De Soto, 1988) e devido aos custos de admissão/demissão decorrentes do contrato formal de trabalho. ${ }^{4}$ Finalmente, os dois bens intermediários são vendidos em um mercado competitivo e não podem ser armazenados. Sendo assim, seus preços são dados pelas respectivas produtividades marginais:

$$
p_{F}=a Y_{F}^{\rho-1} Y^{1-\rho}
$$

4 É uma abordagem comum na literatura considerar os custos de demissão do trabalhador como custos de contratação (ver, por exemplo, HECKMAN; PAGÉS, 2000). 


$$
p_{I}=(1-a) Y_{I}^{\rho-1} Y^{1-\rho}
$$

Cabe notar que as produtividades dependem diretamente da importância relativa de cada setor na produção do bem final (no caso do setor formal, quanto maior o valor do parâmetro $a$, maior será sua produtividade). Sendo assim, ainda que as firmas sejam homogêneas $e x$ ante é possível introduzir uma heterogeneidade produtiva $e x$ post, supondo que aquelas que decidem ingressar no setor informal sofrem uma perda de produtividade. Esta perda é introduzida por hipótese e equivale a supor que $0,5<a<1$. Esta suposição - ainda que não seja necessária para o desenvolvimento do modelo - busca captar alguns elementos importantes relativos à informalidade e que podem causar perdas de produtividade para as firmas informais: a impossibilidade de estas exercerem plenamente seus direitos de propriedade, o que implica, entre outras coisas, problemas de acesso ao crédito; a fiscalização governamental, que leva as firmas informais a manterem suas operações em escalas reduzidas; e a incapacidade destas de se beneficiarem parcial ou integralmente dos bens ofertados pelo governo.

\subsection{O Mercado de Trabalho: a Tecnologia de Matching}

As trocas no mercado de trabalho e a realização dos casamentos entre firmas e trabalhadores em cada setor são representadas por meio de duas funções de matching setoriais. Estas funções são denotadas por $m_{j}\left(u, v_{j}\right), j=I, F$, onde $u$ é a taxa de desemprego da economia e $v_{j}$ é a taxa de abertura de vagas no setor $j .{ }^{5}$ A hipótese subjacente nesta função é que somente os trabalhadores desempregados podem buscar empregos, ou seja, não há busca on-the-job. As funções de matching são dadas por: ${ }^{6}$

$$
m_{j}\left(u, v_{j}\right)=A\left(v_{j}\right)^{1-\eta}(u)^{\eta}, j=I, F
$$

A probabilidade de um trabalhador desempregado conseguir um emprego no setor $j$ é dada por $\lambda_{j}=\frac{m_{j}}{u}=A\left(\theta_{j}\right)^{1-\eta}$, e a probabilidade de uma firma no setor $j$ preencher uma vaga é dada por $q_{j}=\frac{m_{j}}{v_{j}}=A\left(\theta_{j}\right)^{-\eta}, j=I, F .^{7} \mathrm{O}$ parâmetro $\theta_{j}$ representa a "ten-

5 A taxa de abertura de vagas é definida como o número de vagas ofertadas em cada setor relativamente à força de trabalho total.

6 A hipótese de uma função de matching crescente em ambos os argumentos, diferenciável, côncava e homogênea de grau l é padrão na literatura (ver, por exemplo, PISSARIDES, 2000). A forma funcional Cobb-Douglas adotada aqui respeita estas condições e é também freqüentemente adotada.

7 Cabe notar que a forma funcional adotada respeita as hipóteses do tipo Inada que são usualmente feitas, uma vez que: $\lim _{\theta \rightarrow \infty} \lambda_{j}=\infty ; \lim _{\theta \rightarrow 0} \lambda_{j}=0 ; \lim _{\theta \rightarrow \infty} q_{j}=0 ;$ e $\lim _{\theta \rightarrow 0} q_{j}=\infty$. 
são" (tightness) do mercado de trabalho no setor $j$, isto é, o número de vagas no setor vis-à-vis o número de desempregados na economia. Por fim, apresenta-se a hipótese de que todos os casamentos formais e informais são destruídos com probabilidades (exógenas) $s_{F}$ e $s_{I}$, respectivamente, $\operatorname{com} s_{I}>s_{F}{ }^{8}$ Esta hipótese é motivada a partir de evidências empíricas que indicam que as relações de trabalho informais são menos duradouras que as formais (ver AMADEO et al., 2000; NERI, 2002; MENEZESFILHO; CURI, 2006).

Um segundo aspecto, e certamente o mais importante, diz respeito aos argumentos da função de matching. De maneira geral, a literatura considera duas possibilidades para os modelos setoriais de busca e matching: busca não-direcionada (mercados unificados) ou busca direcionada (mercados separados). No primeiro caso, embora existam dois setores no mercado de trabalho ele é analisado de forma unificada: adota-se uma única função de matching para toda a economia, cujos argumentos são as taxas agregadas de criação de vagas e de desemprego. Portanto, é elaborada a hipótese de que os trabalhadores não buscam empregos em um setor especificamente. Além disso, como o argumento da função de matching é a taxa agregada de criação de vagas, ambos os setores apresentam as mesmas probabilidades de as firmas preencherem uma vaga em aberto e de um trabalhador encontrar um emprego. Esta é uma propriedade pouco interessante, especialmente quando se está analisando os mercados de trabalho formal e informal, pois uma das principais características apontadas pelos analistas é exatamente a maior rotatividade do emprego informal e a maior flexibilidade deste setor (ver, por exemplo, MALONEY, 1999). Assim, embora a economia seja composta por dois setores, a estrutura de mercados unificados não permite uma análise mais detalhada de ambos.

No segundo caso (busca direcionada), é feita a separação completa dos mercados, passando a existir duas funções de matching cujos argumentos são as taxas setoriais de criação de vagas e de desemprego. Dessa forma, os mercados deixam de ter qualquer ligação direta, sendo analisados completamente em separado. A única ligação que existe entre ambos é uma "condição de indiferença", uma condição de arbitragem que determina o equilíbrio do modelo: a divisão setorial ocorre no trabalhador que, na margem, é indiferente entre estar desempregado em um setor ou em outro. As desvantagens desta abordagem são bastante claras. Além de não haver ligação direta entre os mercados, é necessário tomar como hipótese a existência de uma taxa de desemprego para cada setor, o que, do ponto de vista econômico e empírico, faz pouco sentido.

8 A hipótese de exogeneidade das taxas de separação é usual na literatura de modelos de matching com dois setores (tais como CAVALCANTI, 2001; FUGAZZA; JACQUES, 2004; BOUEV, 2005). Para uma análise de modelos de matching com um setor e taxa de separação endógena ver, entre outros, Mortensen e Pissarides (1994) e Pissarides (2000). 
A estrutura adotada aqui combina estas duas abordagens, pois utiliza funções de matching setoriais cujo argumento é a taxa agregada de desemprego. Assim, embora os mercados sejam analisados separadamente, os trabalhadores provenientes dos dois setores formam um pool comum de desempregados que buscam empregos formais e informais sem distinção. Portanto, a abordagem proposta aqui possui duas vantagens importantes em relação às anteriores no que diz respeito à análise dos mercados de trabalho formal e informal. A primeira delas é o fato de os mercados serem tratados separadamente, o que permite determinar as tensões de cada mercado, suas taxas de criação de vagas, a probabilidade de entrada e saída do emprego em cada setor e probabilidades distintas de preencher uma vaga em aberto. A segunda vantagem é que, ainda que os mercados sejam analisados separadamente, não é feita a hipótese de busca direcionada. Com isso, não é preciso supor que os trabalhadores podem buscar emprego em apenas um setor (o que não parece verossímil em se tratando dos setores formal e informal) e tampouco supor a existência de duas taxas de desemprego setoriais. Além disso, a hipótese de existência de um pool de desempregados cria um link direto entre ambos os setores, de forma que as condições de oferta e demanda por trabalho em um setor afetam diretamente as decisões dos agentes no outro setor.

\subsection{Caracterização de Trabalhadores e Firmas}

Nesta economia, tanto firmas quanto trabalhadores são caracterizados por equações de Bellman que representam o valor presente descontado associado a cada status possível no mercado de trabalho. Como o foco recai sobre a análise dos efeitos de longo prazo de mudanças institucionais no mercado de trabalho, ao longo de todo o artigo consideramos apenas os valores de steady state das equaçóes de Bellman. Dessa forma, no caso das firmas estas equaçóes representam o valor de uma vaga preenchida $\left(r J_{j}\right)$ ou em aberto $\left(r V_{j}\right)$. No caso dos trabalhadores, elas representam o valor presente descontado do emprego em um determinado setor $\left(r E_{j}\right)$ e o valor esperado da busca por emprego associado ao desemprego e comum a todos $(r U)$. Assim, em steady state, o valor presente descontado de uma vaga preenchida no setor formal, informal e uma vaga em aberto em ambos os setores, respectivamente, é dado pelas seguintes equações:

$$
\begin{aligned}
& r J_{F}=p_{F}-\left(1+\tau_{\pi}\right) w_{F}-s_{F}\left(J_{F}-V_{F}\right) \\
& r J_{I}=p_{I}-w_{I}-s_{I}\left(J_{I}-V_{I}\right) \\
& r V_{j}=q_{j}\left(J_{j}-V_{j}\right), j=I, F
\end{aligned}
$$


No caso das firmas do setor formal, por exemplo, a intuição destas equações (bem como das demais equações de valor do modelo) é que manter uma vaga preenchida é equivalente a deter um ativo. Este ativo paga um dividendo $p_{F}$ do qual deve ser deduzido o salário básico do trabalhador $\left(w_{F}\right)$ acrescido de $\tau_{\pi}$, que é o parâmetro correspondente aos custos não-salariais que incidem sobre o salário formal ( $\mathfrak{w}_{F} \mathrm{e}$ completamente flexível e determinado endogenamente). Como os casamentos em ambos os setores são destruídos de forma aleatória e a uma taxa exógena, há um custo adicional associado às incertezas no retorno destes ativos: uma vaga preenchida no setor formal $\left(J_{F}\right)$ tem probabilidade $s_{F}$ de se transformar em uma vaga em aberto, o que corresponde a uma perda líquida de $\left(J_{F}-V_{F}\right)$. No caso de uma vaga em aberto no setor formal $\left(V_{F}\right)$, há uma probabilidade $q_{F}$ de que ela seja preenchida, o que resulta em um retorno líquido de $\left(J_{F}-V_{F}\right)$. As demais equações de valor nesta seção têm interpretação análoga.

No caso dos trabalhadores, as equações de Bellman em steady state do emprego nos setores formal e informal, respectivamente, e a equação de valor geral do desemprego são dadas por:

$$
\begin{aligned}
& r E_{F}=\left(1-\tau_{\omega}\right) w_{F}-s_{F}\left(E_{F}-U\right)+s_{F} b \\
& r E_{I}=w_{I}-s_{I}\left(E_{I}-U\right) \\
& r U=\lambda_{F}\left(E_{F}-U\right)+\lambda_{I}\left(E_{I}-U\right)
\end{aligned}
$$

onde $\tau_{\omega}$ representa o imposto que incide sobre os trabalhadores e $b$ corresponde ao valor presente descontado do fluxo esperado de recebimento do benefício quando desempregado. ${ }^{9}$

Como foi discutido anteriormente, os trabalhadores egressos de ambos os setores formam um pool de desempregados e, como não há busca direcionada, a equação de valor do desemprego é comum a todos. Ela é composta pela soma dos ganhos líquidos de ingressar no setor formal ou no informal ponderados pelas respectivas probabilidades de entrada em cada setor $\left(\lambda_{j}\right)$. Somente os trabalhadores desempregados egressos do setor formal têm direito ao seguro-desemprego e, por essa razão, ele

9 Claramente, esta modelagem do seguro-desemprego constitui uma forma bastante simplificada de representar o benefício. Porém, alguns aspectos importantes são contemplados, a saber: o fato de o recebimento do benefício estar restrito aos desempregados egressos do setor formal e o fato de o benefício ter um tempo de duração máximo de cinco meses (ver Apêndice). Além disso, cabe ressaltar que esta abordagem é usual na literatura (ver, entre outros, ACEMOGLU, 2001; CAVALCANTI, 2001; BOUEV, 2005; BOERI ; GARIBALDI, 2005). 
entra como um benefício direto ao trabalhador formal através da equação de valor do emprego neste setor [equação (8)].

Dessa forma, os tradeoffs que se apresentam a firmas e trabalhadores são muito claros. Por um lado, estabelecer um contrato informal de trabalho significa evitar uma série de custos decorrentes da legislação trabalhista e, portanto, aumenta o excedente a ser negociado entre firmas e trabalhadores. Por outro lado, a informalidade implica uma instabilidade maior dos contratos de trabalho e uma perda de produtividade que age em sentido contrário aos benefícios mencionados, pois provoca uma redução no excedente produzido.

Os salários são determinados por meio de uma barganha de Nash padrão. Considerando que firmas e trabalhadores são neutros ao risco e possuem a mesma taxa de desconto, as condições de primeira ordem da barganha implicam que os salários dos setores formal e informal são escolhidos de forma que:

$$
(1-\varphi)\left(E_{j}-U\right)=\varphi\left(J_{j}-V_{j}\right), j=F, I
$$

onde $\phi$ denota o poder de barganha dos trabalhadores. ${ }^{10}$

Finalmente, uma vez que há livre-entrada do lado das firmas, não é possível ter lucros esperados positivos com a abertura de um posto de trabalho em qualquer que seja o setor. Assim, podemos escrever o que chamaremos de condição de livre-entrada: $r V_{j}=r K_{j}$.

\subsection{Equações de Salários e as Condições de Arbitragem}

Utilizando a equação (7), as condições de primeira ordem da Barganha de Nash [equação (11)] e a condição de livre-entrada, é possível obter expressões para $E_{I}$ e $E_{F}$, que, ao serem substituídas nas equações de valor do emprego [equações (8) e (9)], permitem obter as equações de salários de ambos os setores:

$$
w_{F}=\frac{1}{1-\tau_{\omega}}\left[\frac{\varphi}{1-\varphi} \frac{\left(r+s_{F}\right)}{q_{F}} r K_{F}+r U-s_{F} b\right]
$$

10 Neste modelo, trabalhadores formais e informais possuem o mesmo poder de barganha, embora seja bastante simples estendê-lo de forma a considerar poderes de barganha diferenciados. Contudo, optouse por esta estrutura para não aumentar a já elevada dimensão paramétrica do modelo. 


$$
w_{I}=\frac{\varphi}{1-\varphi} \frac{\left(r+s_{I}\right)}{q_{I}} r K_{I}+r U
$$

A interpretação das equações de salário é bastante imediata. O salário de ambos os setores é positivamente relacionado com o poder de barganha dos trabalhadores $(\varphi)$ e, no caso do setor formal, com a alíquota que incide sobre os trabalhadores do setor formal $\left(\tau_{\omega}\right)$. Da mesma forma, quanto maiores os custos afundados pelas firmas no momento de criar a vaga $\left(K_{F}\right.$ e $\left.K_{I}\right)$, maior a capacidade dos trabalhadores de negociarem um salário mas elevado (pois o custo para a firma de manter a vaga ociosa é maior) e, portanto, maior o salário de equilíbrio. É importante notar que as equações de salários refletem o "racionamento estocástico" decorrente da existência de fricçóes no mercado de trabalho: o salário de equilíbrio em ambos os setores é inversamente proporcional à probabilidade de preencher uma vaga $\left(q_{j}\right)$ e, portanto, diretamente proporcional às tensões $\theta_{j}$. Isto significa que quanto maior a probabilidade de a firma se deparar com um racionamento de mão-de-obra (que implica um $\theta_{j}$ elevado e um $q_{j}$ pequeno), maior o salário que o trabalhador recebe e vice-versa. Além disso, é importante destacar que embora o seguro-desemprego seja um benefício não-salarial, ele aparece naturalmente como uma forma de remuneração direta para o trabalhador formal. Dessa forma, o seguro-desemprego funciona neste modelo como um subsídio governamental à contratação de trabalhadores formais, pois permite que as firmas paguem salários mais baixos sem incorrer em nenhum custo adicional.

De forma semelhante às equações de salários, a equação de valor do desemprego pode ser reescrita utilizando a equação (7), as condições de primeira ordem da barganha [equação (11)] e a condição de livre-entrada na equação (10). Disso resulta a seguinte expressão:

$$
r U=\frac{\varphi}{1-\varphi}\left(r K_{F} \theta_{F}+r K_{I} \theta_{I}\right)
$$

Intuitivamente, o que acontece é que quanto maiores as tensões de ambos os mercados, $\theta_{F}$ e $\theta_{I}$, mais facilmente os trabalhadores conseguem encontrar um emprego em ambos os setores e, conseqüentemente, maior é o valor do desemprego. Um aspecto importante é o fato de esta equação incluir os parâmetros de tensão $\left(\theta_{j}\right)$ de ambos os mercados. Como foi mencionado anteriormente, a hipótese de existência de um pool de desempregados cria uma conexão imediata entre os dois setores, uma vez que as tensões de ambos os mercados estão afetando diretamente o valor do desemprego 
de todos os trabalhadores. Dessa forma, as equações de salário nos setores formal e informal serão influenciadas não só pelos parâmetros de seu próprio mercado de trabalho, mas também pelos parâmetros do outro mercado.

Passando para as firmas, a partir da equação do valor de uma vaga preenchida nos setores formal ou informal [equaçóes (5) e (6)], da equação (7) e da condição de livre-entrada, obtém-se a condição de arbitragem em ambos os setores:

$$
\begin{aligned}
& p_{F}=\left(1+\tau_{\pi}\right) w_{F}+r K_{F}+\left(r+s_{F}\right) \frac{r K_{F}}{q_{F}} \\
& p_{I}=w_{I}+r K_{I}+\left(r+s_{I}\right) \frac{r K_{I}}{q_{I}}
\end{aligned}
$$

Estas condições de arbitragem implicam que a receita deve se igualar ao custo total da mão-de-obra, somado ao fluxo de custo da criação da vaga. Contudo, em decorrência da existência de fricções no mercado de trabalho, as vagas criadas podem permanecer desocupadas durante algum tempo. Este custo adicional de manter a vaga ociosa (representado pelo último termo do lado direito das equações acima) eleva o preço necessário para garantir que as firmas queiram produzir em ambos os setores. Note que quando $q_{j} \rightarrow \infty$, as firmas conseguem preencher instantaneamente sua vaga e este custo adicional se reduz a zero.

\subsection{O Equilibrio de Steady State}

Ambos os setores existem em equilíbrio e, como cada trabalhador produz apenas uma unidade do bem intermediário, a produção agregada dos setores formal e informal é dada pelo número de trabalhadores empregados em cada setor. Definindo $\gamma$ como a proporção de empregos formais na economia, a produção agregada nos setores formal e informal é dada por: $Y_{F}=\gamma(1-u)$ e $Y_{I}=(1-\gamma)(1-u)$. Logo, pelas equações (2) e (3):

$$
\begin{aligned}
& p_{F}=a \gamma^{\rho-1}\left(a \gamma^{\rho}+(1-a)(1-\gamma)^{\rho}\right)^{\frac{1-\rho}{\rho}} \\
& p_{I}=(1-a)(1-\gamma)^{\rho-1}\left(a \gamma^{\rho}+(1-a)(1-\gamma)^{\rho}\right)^{\frac{1-\rho}{\rho}}
\end{aligned}
$$


Além disso, o equilíbrio de estado estacionário é caracterizado pelos lócus de equilíbrio de ambos os setores, obtidos a partir da substituição das equações de salário (12) e (13) nas condições de arbitragem (15) e (16):

$$
\begin{aligned}
& p_{F}=\frac{1+\tau_{\pi}}{1-\tau_{\omega}}\left[\frac{\varphi}{1-\varphi} \frac{\left(r+s_{F}\right)}{q_{F}} r K_{F}+r U-s_{F} b\right]+\left(r+s_{F}+q_{F}\right) \frac{r K_{F}}{q_{F}} \\
& p_{I}=\frac{\left(r+s_{I}\right)}{(1-\varphi) q_{I}} r K_{I}+r U+r K_{I}
\end{aligned}
$$

Finalmente, para que a economia esteja em equilíbrio nenhum dos dois setores pode estar em expansão ou contração, o que significa que o fluxo de entrada de trabalhadores deve ser igual ao fluxo de saída em cada setor (PISSARIDES, 2000). Com isso, é possível obter condições de equilíbrio para ambos os setores que, conjuntamente, determinam a seguinte condição de fluxo que deve ser respeitada em equilíbrio:

$$
\gamma=f\left(\theta_{F}, \theta_{I}\right)=\frac{\lambda_{F} s_{I}}{\lambda_{F} s_{I}+\lambda_{I} s_{F}}
$$

Com esta última condição é possível caracterizar completamente o equilíbrio do modelo. Igualando as equações das produtividades marginais de equilíbrio [equações (17) e (18)] aos respectivos lócus de equilíbrio [equações (19) e (20)], obtemos duas equações que definem implicitamente $\gamma$ como função de $\theta_{F}$ e $\theta_{I}$. Estas duas equações, associadas à condição de fluxo [equação (2l)], formam um sistema de três incógnitas $-\gamma, \theta_{F}$ e $\theta_{I}-\mathrm{e}$ três equações (ainda que totalmente não-lineares). Este sistema pode ser simplificado ainda mais: substituindo a condição de fluxo [equação (21)] em (17) e (18), obtemos expressões para $p_{F}$ e $p_{I}$ (que denotaremos $\tilde{p}_{F}$ e $\tilde{p}_{I}$ ) como funções unicamente das tensões dos dois mercados: $\tilde{p}_{F}=g\left(f\left(\theta_{F}, \theta_{I}\right)\right)$ e $\tilde{p}_{I}=g\left(f\left(\theta_{F}, \theta_{I}\right)\right)$. Utilizando estas duas expressões e os lócus de equilíbrio de ambos os setores [equações (19) e (20)], é possível escrever o seguinte sistema:

$$
\begin{aligned}
& p_{F}-\tilde{p}_{F}=0 \\
& p_{I}-\tilde{p}_{I}=0
\end{aligned}
$$

Embora seja extremamente difícil encontrar uma solução analítica e provar a existência do equilíbrio deste sistema, os diferentes exercícios numéricos realizados indicam que ele possui equilíbrio e que ele é único e estável (ver Figura l para o caso do modelo parametrizado de acordo com os dados de CAVALCANTI, 2001, para a 
economia norte-americana). ${ }^{11}$ Dessa forma, embora o modelo ganhe em complexidade em relação às estruturas propostas por Acemoglu (2001) e Fugazza e Jacques (2004), a questão da multiplicidade de equilíbrios parece não ser mais tão central. Assim, para analisar os efeitos de mudanças institucionais não é preciso fazer hipóteses acerca do comportamento dos lócus de equilíbrio ou restringir a análise a um determinado intervalo de valores dos parâmetros.

\section{FIGURA I - LÓCUS DE EQUILÍBRIO DOS SETORES FORMAL E INFORMAL}

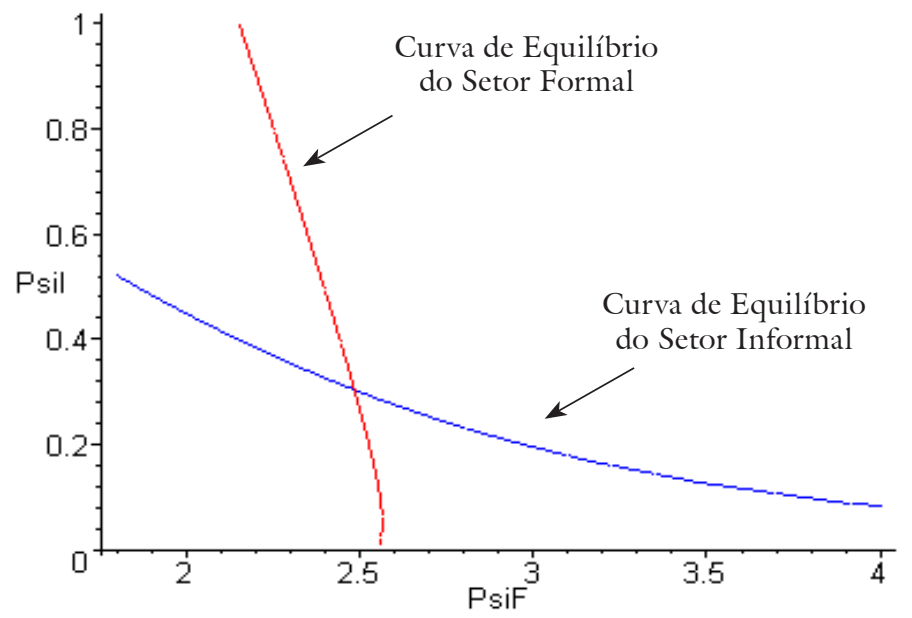

Por outro lado, todas as variáveis de interesse do modelo - o grau de informalidade, a taxa de desemprego, os preços, os salários, entre outros - dependem das condições de oferta e demanda do mercado de trabalho resumidas nas tensões de ambos os setores. Torna-se, portanto, muito difícil obter resultados analíticos a respeito de variações nos parâmetros institucionais que não sejam ambíguos. Como as tensões de ambos os mercados são determinadas endogenamente, elas também são afetadas por mudanças nos parâmetros institucionais e, dependendo de como se dá esse efeito, os resultados podem mudar significativamente.

\subsection{O Diferencial de Salários ao Longo dos Lócus de Equilibrio}

Um dos aspectos mais discutidos na literatura empírica relativa à informalidade no mercado de trabalho é a existência ou não de diferenciais de salários entre trabalhadores formais e informais. Até pouco tempo, um dos fatos estilizados mais bem

11 Além deste, diversos exercícios numéricos foram realizados utilizando diferentes conjuntos de parâmetros. Todos, sem exceção, apresentaram um equilíbrio único e estável, gerando gráficos análogos à Figura 1. O Anexo apresenta alguns dos gráficos correspondentes a diferentes exercícios de simulação realizados tendo a economia brasileira como referência. 
estabelecidos na literatura era a existência destes diferenciais, mesmo considerando as características observáveis e, posteriormente, a existência de viés de seleção.

Contudo, estudos mais recentes mostram que a magnitude e, em alguns casos, o sinal do diferencial de salários entre trabalhadores formais e informais pode variar dependendo do grupo de trabalhadores que se está analisando (ver, por exemplo, TANNURI-PIANTO; PIANTO, 2002; MENEZES-FILHO et al., 2004). No caso do artigo de Menezes Filho et al. (2004), os autores concluem que, condicionado ao nível de escolaridade dos indivíduos, o diferencial de salários é amplamente favorável aos trabalhadores informais. Nesta mesma linha, Maloney (1999) argumenta que para determinados grupos de trabalhadores a informalidade pode estar associada a elevações em seus rendimentos.

Portanto, uma das características pouco desejáveis dos modelos à Acemoglu (2001) é o fato de o diferencial de salários entre trabalhadores formais e informais apresentar sempre um sinal positivo. Portanto, é importante analisar este aspecto dentro da lógica do modelo apresentado. A expressão que determina o diferencial de salários entre os trabalhadores dos setores formal e informal é obtida a partir das equações de salários (12) e (13):

$$
d=\frac{\varphi}{1-\varphi}\left[\frac{\left(r+s_{F}\right) r K_{F}}{\left(1-\tau_{\omega}\right) q_{F}}-\frac{\left(r+s_{I}\right) r K_{I}}{q_{I}}\right]+\frac{\tau_{\omega} \varphi\left(r K_{F} \theta_{F}+r K_{I} \theta_{I}\right)}{\left(1-\tau_{\omega}\right)(1-\varphi)}-\frac{s_{F} b}{\left(1-\tau_{\omega}\right)}
$$

O diferencial de salários possui sinal ambíguo e, como já era possível antecipar a partir das equações (12) e (13), ele irá depender fundamentalmente dos valores dos parâmetros institucionais e das tensões de ambos os mercados. Contudo, pode-se dizer que esta indeterminação do sinal se deve exclusivamente às divergências entre as abordagens aqui adotadas e aquela tradicionalmente adotada na literatura. Esta ambigüidade não pode ser atribuída à presença dos diferentes parâmetros institucionais, pois boa parte deles já está presente no trabalho de Cavalcanti (2001). Sendo assim, esta é mais uma característica particular a este modelo. O diferencial de salários deixa de ser determinístico e passa a depender da demanda por trabalho e das decisões de oferta de trabalho dos indivíduos em ambos os mercados. Este resultado confere uma flexibilidade significativa ao modelo, o que parece se adequar melhor às novas evidências empíricas apresentadas. Por outro lado, torna-se impossível obter resultados qualitativos desses impactos devido ao mesmo tipo de ambigüidade já discutido anteriormente. 


\section{EXERCÍCIOS DE SIMULAÇÃO}

Nesta seção são analisados os efeitos de mudanças na intensidade da fiscalização governamental (via mudanças na taxa de separação do setor informal, $s_{I}$ ), no imposto sobre a folha $\left(\tau_{\pi}\right)$ e no seguro-desemprego $(b)$ sobre as principais variáveis do mercado de trabalho brasileiro, entre as quais: grau de informalidade, desemprego, diferencial de salários, produtividade e produto agregado.

A hipótese por trás deste primeiro exercício é que uma intensificação na fiscalização governamental leva a uma taxa mais elevada de destruição dos postos informais. A justificativa para esta hipótese é bastante imediata: um aumento da fiscalização governamental (por meio, por exemplo, de um aumento no número de fiscais) eleva a probabilidade de deteç̧ão da infração e, portanto, aumenta a probabilidade de que a relação de trabalho informal seja interrompida, o que equivale à probabilidade $s_{I}$ no modelo. Embora a fiscalização governamental não seja o único fator que afeta $s_{I}$, é certamente um dos fatores importantes para a determinação desse parâmetro. Visto de uma forma mais geral, o parâmetro $s_{I}$ pode ser interpretado como uma aproximação do grau de enforcement das instituições do mercado de trabalho. Quanto mais efetivas forem as instituições, e em particular a legislação trabalhista, maior tende a ser o valor do parâmetro $s_{I}$. No limite, um enforcement perfeito deveria levar a que $s_{I}=1$.

Cabe ressaltar, ainda, que essas políticas (notadamente variações na alíquota de imposto sobre a folha e do valor do seguro-desemprego) têm impactos fiscais diretos que, contudo, não são contemplados na análise, visto que não há uma restrição orçamentária do governo. Dito de outra forma, não são consideradas aqui mudanças fiscalmente equilibradas e, portanto, não é possível dizer se tais políticas seriam factíveis do ponto de vista estritamente fiscal, uma vez que o seu custo não está sendo computado. ${ }^{12}$

Os experimentos consistem em resolver o sistema apresentado na Seção 2.5 [equação (22)] para cada novo valor atribuído aos parâmetros de interesse $\left(s_{I}, \tau_{\pi}\right.$ e $\left.b\right)$. Para tanto, é necessário atribuir valores a todos os parâmetros do modelo, caracterizando a economia que servirá de referência. Alguns dos parâmetros do modelo são diretamente observados nos dados ou estimados e outros são extraídos de trabalhos empíricos já realizados, mas uma pequena parte deles deverá ser ajustada na calibra-

12 Para fazer esse tipo de análise, seria necessário desenvolver um modelo de equilíbrio geral computável (CGE) que descrevesse com profundidade a estrutura fiscal brasileira e que apresentasse um lado da produção mais compatível com a economia brasileira. Fernandes et al.. (2004), por exemplo, fazem uma análise dos impactos de diferentes estruturas tributárias sobre o setor formal da economia utilizando, para tanto, um modelo de equilíbrio geral. 
gem do modelo. O conjunto de parâmetros que caracteriza o status quo é dado na Tabela 1 a seguir:

TABELA 1- PARÂMETROS DO STATUS QUO DA ECONOMIA

\begin{tabular}{lrl}
\hline $\begin{array}{l}\text { Parâmetros Observáveis ou Extraídos da } \\
\text { Literatura }\end{array}$ & Valor & \\
\hline Imposto sobre a folha $\left(\tau_{\pi}\right)$ & $35 \%$ & Reis e Ulyssea (2006) \\
Imposto sobre os trabalhadores $\left(\tau_{w}\right)$ & $10 \%$ & Contribuição dos trabalhadores ao INSS \\
Taxa de desconto $(r)$ & $8 \%$ & Heckman e Pagés (2000) \\
Poder de barganha dos trabalhadores $(\phi)$ & $50 \%$ & Valor padrão adotado na literatura \\
Taxa de destruição do setor informal $\left(s_{I}\right)$ & $35 \%$ & Neri (2002); Curi e Menezes-Filho (2004) \\
Taxa de destruição do setor formal $\left(s_{F}\right)$ & $15 \%$ & Courseuil et al. (2002) \\
Parâmetro da função CES $(\rho)$ & 0,3 & Reis e Ulyssea (2006) \\
\hline Parâmetros Estimados & & \\
\hline Custo de criação no setor formal $\left(K_{F}\right)$ & 1,6 & Metodologia de Heckman e Pagés (2000) \\
Custo de criação no setor informal $\left(K_{I}\right)$ & 0,42 & Idem \\
Seguro-desemprego $(b)$ & 0,41 & Idem \\
\hline Parâmetros Calibrados & & \\
\hline Elasticidade da função de matching $(\eta)$ & 0,70 & - \\
Param. de importância relativa de SF $(a)$ & 0,65 & - \\
Param. de escala da função de matching $(A)$ & 0,436 & - \\
\hline Resultados Observáveis & & Idem \\
\hline Taxa de desemprego $(u)$ & $17,4 \%$ & PNAD 2003 \\
Grau de informalidade $[(1-\gamma)(1-u)]$ & $31,6 \%$ & Idem \\
Grau de formalidade $[\gamma(1-u)]$ & $51,0 \%$ & Idem \\
\hline
\end{tabular}

A taxa de destruição dos empregos formais apresentada na Tabela l é uma aproximação obtida a partir dos resultados apresentados por Corseuil et al.. (2002), enquanto a taxa de destruição do setor informal foi atribuída a partir de uma série de dados apresentados por Neri (2002) e Curi e Menezes-Filho (2004), em particular das matrizes de transição construídas por Neri. Como este último diferencia as taxas de transição do emprego informal para o desemprego e para outra ocupação qualquer, os valores obtidos refletem somente a taxa de saída do emprego informal para o desemprego. O parâmetro da função CES $(\rho)$ é obtido a partir dos valores estimados em Reis e Ulyssea (2006). Devido à sua importância, foram feitos testes de robustez 
dos resultados utilizando os valores $\rho=0,2$ e $\rho=0,4$ (os resultados encontram-se no Apêndice II).

O valor da taxa de desconto é o mesmo utilizado por Heckman e Pagés (2000) para diferentes países da América Latina e que também é empregado na estimativa dos valores dos custos de criação de ambos os setores e do valor presente descontado do seguro-desemprego (a metodologia empregada está discutida em detalhe no Apêndice). O poder de barganha dos trabalhadores é o mais comumente usado na literatura (ver CAVALCANTI, 2001, ou MORTENSEN; PISSARIDES, 1994). ${ }^{13}$ Finalmente, os parâmetros $A, \eta$ e $a$ são calibrados de forma que o equilíbrio do modelo forneça os valores da taxa de desemprego, grau de informalidade e grau de formalidade indicados nas três últimas linhas da Tabela 1 (17,4\%, 31,6\% e 51\%, respectivamente). ${ }^{14}$ Estas variáveis são determinadas a partir dos dados da $\mathrm{PNAD} / 2003^{15}$ e utilizando a definição de população adotada no modelo, ou seja, o universo de trabalhadores corresponde aos trabalhadores com carteira, sem carteira e desempregados. O grau de informalidade é definido como o número de trabalhadores sem carteira de trabalho assinada sobre o total da população considerada. O análogo vale para o grau de formalidade e taxa de desemprego.

Assim, o conjunto de valores dos parâmetros apresentado na Tabela 1 caracteriza o equilíbrio inicial (status quo) que constituirá o ponto de partida dos exercícios de simulação.

\subsection{Resultados}

\subsubsection{Seguro-Desemprego}

Na Tabela 2 a seguir são apresentados os resultados dos experimentos relativos a variações no valor do seguro-desemprego.

13 Foram utilizados diferentes valores para o poder de barganha que variaram de 0,15 a 0,5. Embora os níveis das variáveis se alterem (em particular a taxa de desemprego - crescente em $\phi$ ), a direção e intensidade de todos os resultados se mantêm. Por isso, optou-se por utilizar o valor mais comumente encontrado na literatura.

14 Foram feitos diferentes exercícios de robustez (não reportados) com o objetivo de avaliar a sensibilidade dos resultados a diferentes valores de $A, \eta$ e $a$. Os exercícios mostraram que os resultados são bastante robustos a $\eta$ e $A$, mas, como seria lícito esperar, o parâmetro $a$ tem um impacto mais significativo tanto sobre a composição do emprego quanto sobre o diferencial de salários. Não obstante, nesse caso também a direção e a intensidade dos efeitos apresentados nas subseções seguintes se mantêm inalteradas.

15 Além de 2003, todos os exercícios foram realizados utilizando os dados da PNAD/1999 e os resultados se mostraram robustos. 
TABELA 2 - RESULTADOS DE VARIAÇÕES NO SEGURO-DESEMPREGO

\begin{tabular}{lccccc}
\hline Variáveis & $b=0$ & $b=0,2$ & $\begin{array}{c}b=0,41 \\
\text { (eq. inicial) }\end{array}$ & $b=0,6$ & $b=0,8$ \\
\hline Desemprego (\%) & 18,2 & 17,8 & 17,4 & 17,1 & 16,9 \\
Grau de Formalidade (\%) & 48,4 & 49,8 & 51,0 & 52,2 & 53,3 \\
Grau de Informalidade (\%) & 33,4 & 32,4 & 31,6 & 30,7 & 29,8 \\
Diferencial (\%) & 1,1 & $-6,2$ & $-13,3$ & $-19,0$ & $-24,7$ \\
Índice de Produto (status quo=1) & 0,983 & 0,992 & 1,000 & 1,006 & 1,012 \\
Índice de Produtiv. ${ }^{1}$ (status quo=1) & 0,992 & 0,996 & 1,000 & 1,002 & 1,005 \\
Pr (Desemp. $\rightarrow$ EF) (\%) & 40,0 & 42,0 & 43,9 & 45,6 & 47,3 \\
Pr (Desemp. $\rightarrow$ EI) & 64,3 & 63,8 & 63,3 & 62,6 & 61,9 \\
Prob. Preencher Vaga Formal $\left(q_{F}\right)(\%)$ & 53,3 & 47,6 & 42,8 & 39,1 & 36,0 \\
Prob. Preencher Vaga Informal $\left(q_{I}\right)(\%)$ & 17,6 & 17,9 & 18,3 & 18,7 & 19,2 \\
\hline
\end{tabular}

${ }^{1}$ A medida de produtividade é definida de acordo com Acemoglu (2001): $\left[(1-u)(1-\gamma) p_{F}+\gamma(1-u) p_{I}\right]$.

Nitidamente, os efeitos mais significativos são observados sobre os salários dos trabalhadores formais e, conseqüentemente, sobre o diferencial de salários entre os dois setores - que apresenta uma variação total de aproximadamente 26 pontos percentuais (p.p.). Isto decorre do fato de o seguro-desemprego ser contabilizado como uma forma de rendimento não-salarial do trabalhador formal e, portanto, reduções neste benefício são compensadas por elevações no salário contratual formal. Analogamente, quando ocorre um aumento em $b$ o salário formal ajusta para baixo. Dessa forma, fica claro o papel de subsídio à contratação de trabalhadores formais desempenhado pelo seguro-desemprego.

Em função disto, o aumento no seguro-desemprego não apresenta o efeito tradicionalmente encontrado na literatura de elevar a duração e, conseqüentemente, a taxa de desemprego da economia. Ao contrário, devido a esta característica de subsídio, um aumento em $b$ tem um efeito positivo sobre o emprego formal (5 p.p.) e negativo sobre o informal (3,6 p.p.), melhorando a composição do emprego na economia e reduzindo levemente a taxa de desemprego (1,3 p.p.). Esta redução no desemprego é em parte explicada pelo fato de o aumento na probabilidade de saída do desemprego para um emprego formal mais do que compensar a redução na probabilidade de saída para um emprego informal, levando a uma redução na duração do desemprego. Finalmente, elevações no seguro-desemprego estão associadas a pequenos aumentos no nível de produtividade da economia. 
Estes resultados estão de acordo com Acemoglu (2001), pois um dos principais resultados apresentados pelo autor é o efeito positivo da introdução do segurodesemprego sobre a composição do emprego e sobre a produtividade média da economia, ${ }^{16}$ apesar de gerar um aumento na taxa de desemprego. Contudo, o autor não consegue verificar o efeito líquido sobre o bem-estar da economia, pois os resultados analíticos são sempre ambíguos. Da mesma forma, Fugazza e Jacques (2004) encontram um efeito positivo do seguro-desemprego sobre a composição do emprego e sobre o desemprego. Ao contrário, Cavalcanti (2001) conclui, através de seus experimentos quantitativos, que o efeito sobre a composição do emprego é negativo, pois uma elevação do benefício resultaria em um aumento significativo na proporção de empregos informais. Além disso, em oposição aos resultados apresentados acima, o autor conclui que um valor mais elevado para o seguro-desemprego levaria a uma redução da produtividade da economia. A razão das diferenças nas conclusões apresentadas reside em duas hipóteses cruciais feitas por Cavalcanti: (i) trabalhadores informais podem continuar recebendo o seguro-desemprego mesmo depois de empregados; e (ii) qualquer trabalhador desempregado pode recebê-lo, independentemente do tipo de trabalho que possuía quando empregado. Assim, uma elevação do benefício aumenta de forma trivial a atratividade do emprego informal, pois eleva diretamente a possibilidade de rendimentos neste setor.

\subsubsection{Fiscalização Governamental}

Considerando agora uma política de intensificação da fiscalização por parte do governo, é possível observar que esta tem efeitos muito expressivos sobre a composição formal-informal e sobre a taxa de desemprego da economia.

Com uma elevação de quase $100 \%$ na taxa de destruição dos postos de trabalho informais seria possível reduzir o grau de informalidade em cerca de $33 \%$ (ou 10 p.p.). Por outro lado, essa política levaria a uma elevação de quatro pontos percentuais na taxa de desemprego, o que se deve em parte ao aumento na taxa de saída do emprego informal para o desemprego e em parte à redução de 3,6 pontos percentuais na probabilidade de saída do desemprego para um emprego formal. Desse forte efeitocomposição e da substancial elevação do desemprego decorrem os efeitos negativo sobre o produto e positivo sobre a produtividade. Por um lado, a participação do setor mais produtivo (o setor formal) no total de empregos aumenta significativa-

$16 \mathrm{O}$ autor considera este benefício como uma renda lump sum recebida por todos os trabalhadores desempregados, independentemente do setor em que eles estavam empregados anteriormente. Portanto, um valor mais generoso do seguro-desemprego permite que os trabalhadores esperem por mais tempo por um emprego com uma remuneração maior (um "bom" emprego na nomenclatura do autor), ao invés de aceitarem rapidamente um "mau" emprego. Isso faz com que o salário do setor de empregos ruins se eleve, provocando uma redução no tamanho relativo deste setor e a conseqüiente melhora na composição do emprego. 
mente - levando ao pequeno aumento observado na produtividade média da economia (1,2\%); por outro, há uma redução na taxa de utilização da força de trabalho (aumento do desemprego) que leva a uma redução de $3,6 \%$ no produto total.

\section{TABELA 3 - RESULTADOS DE INTENSIFICAÇÃO DA FISCALIZAÇÃO GOVERNAMENTAL}

\begin{tabular}{|c|c|c|c|c|}
\hline Variáveis & $\begin{array}{c}s_{I}=0,35 \\
\text { (eq. inicial) }\end{array}$ & $s_{I}=0,45$ & $s_{I}=0,55$ & $s_{I}=0,65$ \\
\hline Desemprego (\%) & 17,4 & 19,0 & 20,3 & 21,3 \\
\hline Grau de Formalidade (\%) & 51,0 & 53,6 & 55,6 & 57,1 \\
\hline Grau de Informalidade (\%) & 31,6 & 27,4 & 24,1 & 21,6 \\
\hline Diferencial (\%) & $-13,3$ & $-21,6$ & $-28,2$ & $-33,7$ \\
\hline Índice de Produto (status quo=1) & 1,000 & 0,989 & 0,977 & 0,964 \\
\hline Índice de Produtiv. ${ }^{1}$ (status quo=1) & 1,000 & 1,009 & 1,012 & 1,012 \\
\hline $\operatorname{Pr}($ Desemp. $\rightarrow \mathrm{EF})(\%)$ & 43,9 & 42,3 & 41,1 & 40,3 \\
\hline $\operatorname{Pr}($ Desemp. $\rightarrow$ El) & 63,3 & 64,8 & 65,5 & 65,8 \\
\hline Prob. Preencher Vaga Formal $\left(q_{F}\right)(\%)$ & 42,8 & 46,7 & 50,0 & 52,5 \\
\hline Prob. Preencher Vaga Informal $\left(q_{1}\right)(\%)$ & 18,3 & 17,3 & 16,8 & 16,7 \\
\hline
\end{tabular}

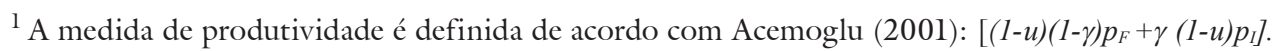

Assim, o fortalecimento das instituiçôes e de sua efetividade diante do comportamento dos agentes - tornando as relações de trabalho informais mais arriscadas e instáveis - parece ser um instrumento poderoso para reduzir o grau de informalidade da economia. Entretanto, essa política gera efeitos negativos sobre o desemprego e produto, levando, em última instância, a um tradeoff entre grau de formalização, produtividade e nível de produto e desemprego.

\subsubsection{Imposto Sobre a Folba}

Como mostra a Tabela 4, variações nos custos não-salariais da mão-de-obra produzem efeitos particularmente reduzidos sobre a taxa de desemprego e, em menor medida, sobre o grau de formalização do mercado de trabalho. Por outro lado, mudanças no valor de $\tau_{\pi}$ afetam significativamente o diferencial de salários entre os dois setores, o que mostra que ajustes diante de variações na alíquota recaem fundamentalmente sobre salários e não sobre o emprego. 


\section{TABELA 4 - IMPOSTO SOBRE A FOLHA}

\begin{tabular}{lccccccc} 
Variáveis & $\pi_{\pi}=0,15$ & $\pi_{\pi}=0,2$ & $\pi_{\pi}=0,25$ & $\pi_{\pi}=0,3$ & $\pi_{\pi}=0,35^{\mathrm{a}}$ & $\pi_{\pi}=0,4$ & $\pi_{\pi}=0,45$ \\
& & & & & & & \\
\hline Desemprego (\%) & 17,0 & 17,2 & 17,2 & 17,3 & 17,4 & 17,5 & 17,6 \\
Grau de Formalidade (\%) & 52,7 & 52,2 & 51,8 & 51,4 & 51,0 & 50,7 & 50,3 \\
Grau de Informalidade (\%) & 30,3 & 30,6 & 31,0 & 31,3 & 31,6 & 31,8 & 32,1 \\
Diferencial (\%) & $-8,1$ & $-9,4$ & $-10,7$ & $-12,0$ & $-13,3$ & $-14,4$ & $-15,6$ \\
Índice de Produto (status quo=1) & 1,009 & 1,007 & 1,004 & 1,002 & 1,000 & 0,998 & 0,995 \\
Índice de Produtiv. ${ }^{1}$ (status quo=1) & 1,004 & 1,003 & 1,002 & 1,001 & 1,000 & 0,999 & 0,998 \\
Pr (Desemp. $\rightarrow$ EF) (\%) & 46,4 & 45,8 & 45,1 & 44,5 & 43,9 & 43,4 & 42,8 \\
Pr (Desemp. $\rightarrow$ EI) (\%) & 62,3 & 62,6 & 62,8 & 63,1 & 63,3 & 63,5 & 63,6 \\
Prob. Preencher Vaga SF (qF) (\%) & 42,8 & 38,9 & 40,2 & 41,5 & 42,8 & 44,1 & 45,4 \\
Prob. Preencher Vaga SI (q) (\%) & 18,3 & 18,7 & 18,6 & 18,4 & 18,3 & 18,1 & 18,0 \\
\hline
\end{tabular}

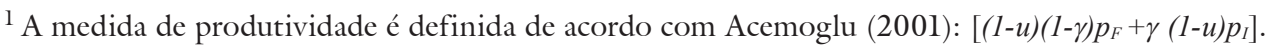

A literatura que trata dos efeitos do imposto sobre a folha relativamente ao emprego, desemprego e salários é ambígua. Há desde trabalhos indicando que mudanças no imposto são totalmente ajustadas via salários, até artigos que mostram que há efeitos substanciais sobre o nível e a composição do emprego (KUGLER; KUGLER, 2003). No caso brasileiro, no primeiro grupo há o trabalho de Fernandes et al.. (2004), que utiliza um modelo de equilíbrio geral para simular os impactos de mudanças na estrutura tributária do País e também concluem que reduções na alíquota sobre o trabalho não teriam impactos significativos sobre o emprego formal. No segundo grupo, Reis e Ulyssea (2006) verificam que mudanças no imposto sobre a folha teriam impactos substanciais sobre o desemprego e sobre o grau de informalidade da economia.

As razões para as divergências entre os resultados apresentados aqui e em Reis e Ulyssea (2006) decorrem essencialmente do fato de que, no presente modelo, os salários em ambos os setores são completamente flexíveis, ao contrário do que ocorre nesse segundo artigo. Como destacado em Reis e Ulyssea (2006), o grau de flexibilidade dos salários é central na determinação de como ocorrerá o ajuste diante de variações no imposto sobre a folha. Quanto mais rígidos forem os salários no setor formal, maior será o impacto sobre a composição do emprego (entre os setores formal e informal) e sobre o desemprego. Ao contrário, se o salário real for totalmente flexível, variações no imposto sobre a folha tendem a ser completamente 
compensadas por variações no preço (salário), enquanto a quantidade (emprego) pouco se altera.

\section{CONSIDERAÇÕES FINAIS}

Ao longo deste artigo desenvolveu-se um modelo de matching com dois setores (formal e informal) em que a composição do emprego, a taxa de desemprego, o diferencial de salários e uma série de outros resultados centrais do mercado de trabalho são determinados de forma endógena. O modelo incorpora os principais tradeoffs com que firmas e trabalhadores se defrontam no momento de decidir em que setor ingressar. Além disso, considera explicitamente os efeitos das condições de oferta e demanda por trabalho em cada setor sobre as decisões dos agentes, enfatizando as interações entre as decisões de firmas e trabalhadores e o papel das instituições na determinação dos resultados do mercado de trabalho.

Este trabalho relaciona-se com a literatura de modelos setoriais de matching, em particular aqueles aplicados à análise do setor informal. Contudo, a estrutura aqui apresentada inclui uma inovação que torna o modelo mais coerente com alguns fatos estilizados importantes relativos à informalidade no mercado de trabalho. Ao contrário do que é usualmente feito, os mercados de trabalho formal e informal são analisados de forma separada (com funções de matching setoriais), mas sem a hipótese de que a busca por parte dos trabalhadores é direcionada para um único mercado. Os desempregados formam um pool de trabalhadores que buscam empregos formais e informais sem distinção. Além de eliminar a necessidade de supor busca direcionada por parte dos trabalhadores e a existência de taxas de desemprego distintas para os setores formal e informal, a estrutura apresentada cria uma ligação direta entre ambos os mercados e confere ao modelo uma flexibilidade que parece estar de acordo com as evidências empíricas mais recentes.

Não obstante, com esta nova estrutura torna-se muito difícil obter resultados analíticos que não sejam ambíguos. Ainda assim, a análise numérica indica que o equilíbrio do modelo é único e estável para um amplo espectro de valores dos parâmetros, reduzindo, assim, a importância da questão da multiplicidade de equilíbrios presente em Acemoglu (2001), Cavalcanti (2001) e Fugazza e Jacques (2004).

As simulações de impactos de políticas apresentam resultados importantes. Entre estes, destaca-se o papel de subsídio à contratação de trabalhadores formais desempenhado pelo seguro-desemprego e o conseqüente impacto positivo sobre a composição do emprego e sobre o desemprego diante de elevações neste benefício. Contudo, os resultados mostram que se trata de uma política de baixa efetividade, uma vez que 
grandes aumentos no benefício têm efeitos positivos muito reduzidos sobre os indicadores do mercado de trabalho. $\mathrm{O}$ mesmo pode ser dito em relação aos impactos de reduções na alíquota de imposto sobre a folha. Embora apresentem efeitos positivos sobre a composição do emprego, com uma redução do grau de informalidade, estes são muito reduzidos. Quase todo o efeito de variações na alíquota de imposto sobre a folha recai sobre os salários dos trabalhadores.

Finalmente, em relação à intensificação da fiscalização governamental sobre os postos de trabalho informais, os resultados indicam que esta política pode ser bastante efetiva na redução do grau de informalidade no mercado de trabalho brasileiro. Porém, estas reduções ocorrem de forma concomitante com uma deterioração de indicadores fundamentais do mercado de trabalho, em particular a taxa de desemprego e o produto total.

Assim, os resultados sugerem que a redução da informalidade não pode ser considerada como um objetivo em si, pois ela não está necessariamente associada a um melhor desempenho do mercado de trabalho. Ao contrário, dependendo da política utilizada para reduzir a informalidade, os efeitos sobre outros indicadores podem ser extremamente negativos. Portanto, é preciso considerar de forma integrada os efeitos de políticas e mudanças institucionais para que seja possível comparar os cenários contrafactuais associados a diferentes níveis de informalidade no mercado de trabalho brasileiro. 


\section{ANEXO}

FIGURA A.I - CURVAS DE EQUILÍBRIO DOS SETORES FORMAL E INFORMAL $(b=0)$

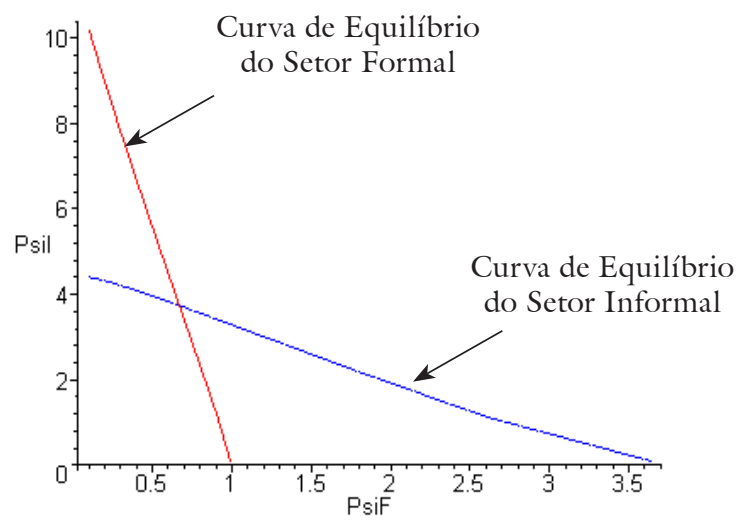

FIGURA A.2 - CURVAS DE EQUILÍBRIO DOS SETORES FORMAL E INFOR MAL (STATUS QUO, $b=0,41$ )

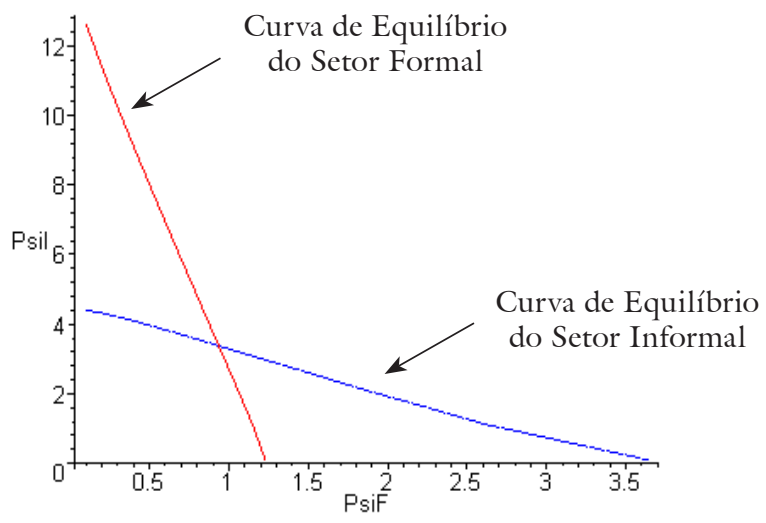


FIGURA A.3 - CURVAS DE EQUILÍBRIO DOS SETORES FORMAL E INFORMAL $(b=0,8)$

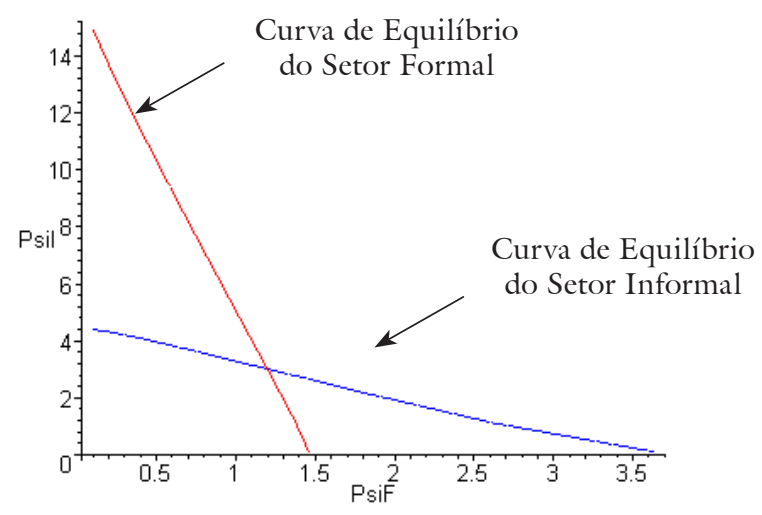

FIGURA A.4 - CURVAS DE EQUILÍBRIO DOS SETORES FORMALE INFORMAL

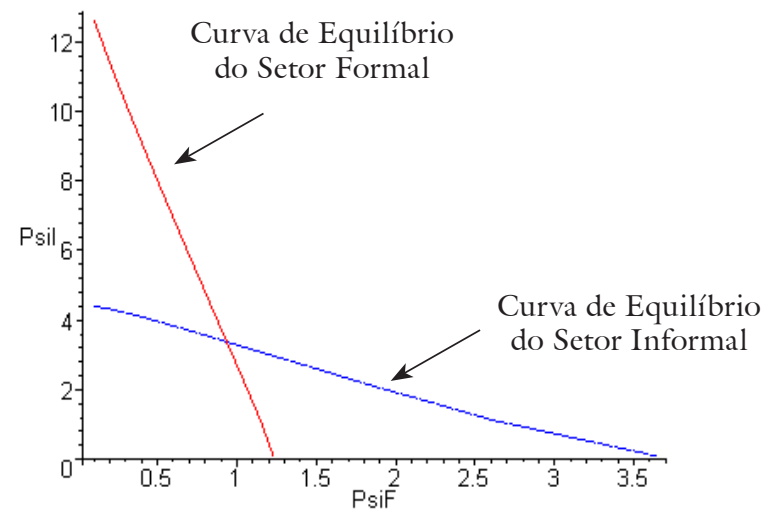

FIGURA A.5 - CURVAS DE EQUILÍBRIO DOS SETORES FORMAL E INFORMAL

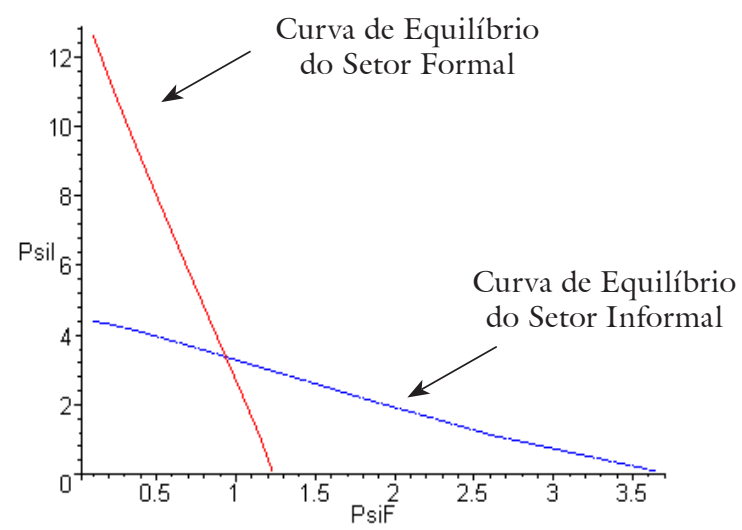


FIGURA A.6 - CURVAS DE EQUILÍBRIO DOS SETORES FORMAL E INFORMAL

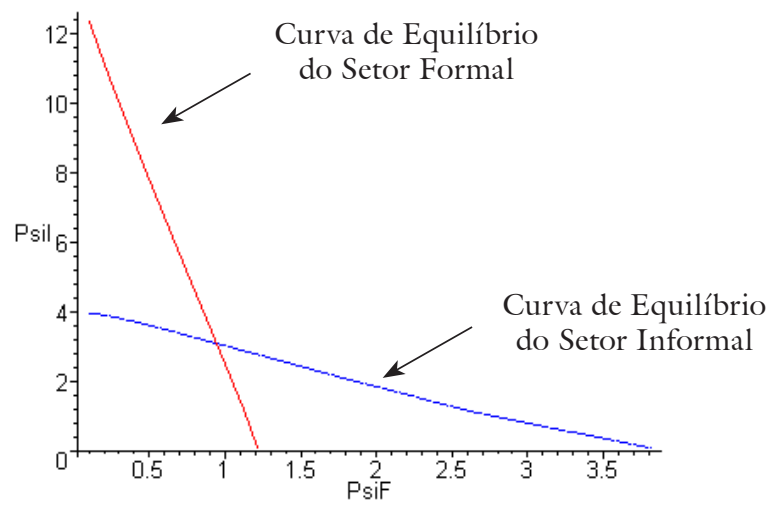

\section{APENDICE 1}

\subsection{Estimação dos Parâmetros KF, KI e b}

A metodologia utilizada para obter o valor destes três parâmetros segue Heckman e Pagés (2000). Estes autores utilizam um índice cardinal que resume os principais custos de demissão dos países da América Latina e que é construído a partir da seguinte fórmula:

$$
I_{j, t}=\sum_{i=1}^{T} \beta^{i} \delta^{i-1}(1-\delta)\left(b_{j, t+1}+a S P_{j, t+1}^{j c}+(1-a) S P_{j, t+1}^{u c}\right)
$$

onde $j$ denota o país, $\delta$ a probabilidade de permanecer no emprego, $\beta$ é o fator de desconto, $T$ é a duração máxima de uma relação de trabalho, $b_{j, t+l}$ é o aviso prévio pago a um trabalhador que permaneceu durante $i$ anos na firma, $a$ é a probabilidade de "dificuldades econômicas das firmas" ser considerado um fator que caracteriza demissão por justa causa, $S P_{j, t+1}^{j c}$ é a multa por demissão quando há justa causa para um trabalhador que permaneceu $i$ anos na firma e, finalmente, $S P_{j, t+1}^{u c}$ é a multa por demissão quando não há justa causa, para um trabalhador que permaneceu $i$ anos na firma. Este índice mede o custo esperado descontado de demitir o trabalhador no futuro, avaliado no momento de sua contratação.

Ao estimar este índice, os autores adotaram taxas de desconto e rotatividade comuns a todos os países de $8 \%$ e $12 \%$, respectivamente. Nos países em que justificativas associadas às condições econômicas não configuram demissões por justa causa - que 
é o caso brasileiro - atribuiu-se o valor zero para o parâmetro $a$. O valor obtido para este índice no caso brasileiro é de 1,8 vezes o salário mensal médio dos trabalhadores formais. De acordo com a PNAD/2003, o rendimento médio do trabalho principal dos trabalhadores com carteira de trabalho assinada correspondia a $\mathrm{R} \$ 819,00$ (em $\mathrm{R} \$$ de 2003), o que resulta em $K_{F}=1,8 \times 819=1.474,2$.

Para obter o valor de $b$ também foi adotada a metodologia apresentada acima, enquanto o valor de $K_{I}$ baseou-se na notação de Gonzaga (2003) e em algumas hipóteses importantes acerca dos efeitos do funcionamento da Justiça do Trabalho sobre o comportamento dos agentes. A construção do indicador dos custos de criação de um posto de trabalho no setor informal partiu da premissa de que os custos de demissão neste setor não são nulos. A forma como está estruturada a justiça do trabalho no Brasil fornece uma legalidade ex post para os contratos informais, pois todo trabalhador contratado informalmente tem direito de ir aos tribunais trabalhistas exigir os direitos suprimidos ao longo da relação de trabalho, inclusive os aspectos relativos aos custos de demissão (aviso prévio e a multa de $40 \%$ sobre o saldo do FGTS). Sendo assim, os custos de criação de um posto de trabalho informal - que aqui são exclusivamente interpretados como custos de demissão - dependem não só da duração média das relações de trabalho, como também da probabilidade de os trabalhadores recorrerem à justiça e da parcela das demandas trabalhistas que em média é paga pelos empregadores:

$$
\begin{aligned}
& K_{I}=(1+1,4 \times 2) \times 0,4 \times 0,56=0,8512 \\
& b=\sum_{i=1}^{5}\left(\frac{1}{1,08}\right)^{i} \times(0,226)^{i-1} \times 0,57 \times i=1,157
\end{aligned}
$$

Em $K_{I}$, considerou-se uma duração média do emprego de dois anos, uma probabilidade de ocorrência de um processo na justiça do trabalho de $57 \%$ e uma parcela das reivindicações totais efetivamente pagas pelos empregadores de $40 \%$ (estes percentuais foram estabelecidos a partir dos dados apresentados por CAMARGO, 2002). Finalmente, em $b$ foi utilizada uma probabilidade de saída do desemprego de 55\% - valor aproximado a partir dos dados da PME e dos resultados de Neri (2002) - e a duração máxima do benefício no Brasil, que é de cinco meses.

Feito isso, é preciso calcular o valor monetário total de ambos os parâmetros. Segundo a PNAD/2003, o rendimento médio do trabalho principal dos trabalhadores sem carteira de trabalho assinada correspondia a R $\$ 464,09$ (em reais de 2003), o que resulta em $K_{I}=0,8512 \times 464,09=395,04$. Quanto ao seguro-desemprego, o valor médio do benefício em 2003 era de 1,4 salário mínimo (fonte: Ministério do 
Trabalho e Emprego) o que, considerando um salário mínimo igual a $\mathrm{R} \$ 240,00$ (em 2003), corresponde a um valor total de R $\$ 336,00$. Logo, $b=1,157 \times 336=$ 388,65 .

Com tudo isso, é possível estabelecer uma relação cardinal entre os parâmetros $K_{F}, K_{I}$ e $b$ a partir dos valores monetários obtidos acima. É fácil ver, por exemplo, que $K_{I}$ e $b$ correspondem a aproximadamente $27 \%$ e $26 \%$ do valor de $K_{F}$, respectivamente. Para adequar o valor destes parâmetros à escala do modelo, o valor de $K_{F}$ é fixado em 1,6 e a partir daí os valores $K_{I}$ e $b$ são estabelecidos de forma que a cardinalidade entre os três se mantenha. Desse processo resultam os números utilizados nas simulações, $K_{I}=0,42(0,42 \div 1,6=0,263)$ e $b=0,41(0,41 \div 1,6=0,256)$.

APÊNDICE 2

\subsection{Testes de Robustez}

TABELA A.I - SEGURO DESEMPREGO

\begin{tabular}{|c|c|c|c|c|c|c|c|c|c|}
\hline \multirow[b]{2}{*}{ Variáveis } & \multicolumn{3}{|c|}{$\sigma=0,2$} & \multicolumn{3}{|c|}{$\sigma=0,3^{\mathrm{a}}$} & \multicolumn{3}{|c|}{$\sigma=0,4$} \\
\hline & $b=0,2$ & $b=0,41$ & $b=0,6$ & $b=0,2$ & $b=0,41^{a}$ & $b=0,6$ & $b=0,2$ & $b=0,41$ & $b=0,6$ \\
\hline Desemprego (\%) & 17,8 & 17,5 & 17,2 & 17,8 & 17,4 & 17,1 & 17,7 & 17,4 & 17,1 \\
\hline Grau de Formal (\%) & 49,2 & 50,4 & 51,5 & 49,8 & 51,0 & 52,2 & 50,4 & 51,8 & 52,9 \\
\hline Grau de Informal (\%) & 33,0 & 32,1 & 31,3 & 32,4 & 31,6 & 30,7 & 31,9 & 30,8 & 30,0 \\
\hline Diferencial (\%) & $-7,7$ & $-14,8$ & $-20,7$ & $-6,2$ & $-13,3$ & $-19,0$ & $-4,5$ & $-11,4$ & $-17,2$ \\
\hline Índice de Produto & 0,992 & 1,000 & 1,006 & 0,992 & 1,000 & 1,006 & 0,992 & 1,000 & 1,006 \\
\hline Índice de Produtiv. ${ }^{1}$ & 0,997 & 1,000 & 1,002 & 0,996 & 1,000 & 1,002 & 0,996 & 1,000 & 1,003 \\
\hline $\operatorname{Pr}($ Desemp. $\rightarrow$ EF) $(\%)$ & 41,4 & 43,3 & 45,0 & 42,0 & 43,9 & 45,6 & 42,6 & 44,7 & 46,4 \\
\hline $\operatorname{Pr}($ Desemp. $\rightarrow$ EI) $(\%)$ & 64,7 & 64,3 & 63,8 & 63,8 & 63,3 & 62,6 & 62,9 & 62,1 & 61,2 \\
\hline $\begin{array}{l}\text { Prob. Preencher Vaga } \\
\operatorname{SF}\left(q_{F}\right)(\%)\end{array}$ & 49,3 & 44,3 & 40,5 & 47,6 & 42,8 & 39,1 & 45,9 & 41,2 & 37,7 \\
\hline $\begin{array}{l}\text { Prob. Preencher Vaga } \\
\text { SI }\left(q_{1}\right)(\%)\end{array}$ & 17,3 & 17,6 & 17,9 & 17,9 & 18,3 & 18,7 & 18,5 & 19,1 & 19,7 \\
\hline
\end{tabular}

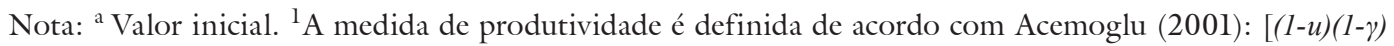
$\left.p_{F}+\gamma(1-u) p_{I}\right]$. 
TABELA A.2 - INTENSIFICAÇÃO DA FISCALIZAÇÃO GOVERNAMENTAL

\begin{tabular}{|c|c|c|c|c|c|c|c|c|c|}
\hline & \multicolumn{3}{|c|}{$\sigma=0,2$} & \multicolumn{3}{|c|}{$\sigma=0,3^{\mathrm{a}}$} & \multicolumn{3}{|c|}{$\sigma=0,4$} \\
\hline Variáveis & $s_{I}=0,35$ & $s_{I}=0,45$ & $s_{I}=0,55$ & $s_{I}=0,35^{a}$ & $s_{I}=0,45$ & $s_{I}=0,55$ & $s_{I}=0,35$ & $s_{I}=0,45$ & $s_{I}=0,55$ \\
\hline Desemprego (\%) & 17,5 & 19,1 & 20,5 & 17,4 & 19,0 & 20,3 & 17,4 & 18,9 & 20,0 \\
\hline Grau de Formal.(\%) & 50,4 & 52,8 & 54,6 & 51,0 & 53,6 & 55,6 & 51,8 & 54,5 & 56,7 \\
\hline Grau de Informal.(\%) & 32,1 & 28,1 & 24,9 & 31,6 & 27,4 & 24,1 & 30,8 & 26,6 & 23,3 \\
\hline Diferencial (\%) & $-14,8$ & $-23,7$ & $-30,7$ & $-13,3$ & $-21,6$ & $-28,2$ & $-11,4$ & $-19,1$ & $-25,3$ \\
\hline Índice de Produto & 1,000 & 0,987 & 0,972 & 1,000 & 0,989 & 0,977 & 1,000 & 0,992 & 0,983 \\
\hline Índice de Produtiv. ${ }^{1}$ & 1,000 & 1,007 & 1,009 & 1,000 & 1,009 & 1,012 & 1,000 & 0,010 & 1,015 \\
\hline $\operatorname{Pr}($ Desemp. $\rightarrow$ EF) $(\%)$ & 43,3 & 41,4 & 39,9 & 43,9 & 42,3 & 41,1 & 44,7 & 43,3 & 42,4 \\
\hline $\operatorname{Pr}($ Desemp. $\rightarrow$ EI) $(\%)$ & 64,3 & 66,0 & 66,9 & 63,3 & 64,8 & 65,5 & 62,1 & 63,3 & 63,8 \\
\hline $\begin{array}{l}\text { Prob. Preencher Vaga } \\
\operatorname{SF}\left(q_{F}\right)(\%)\end{array}$ & 44,3 & 49,3 & 53,5 & 42,8 & 46,7 & 50,0 & 41,2 & 44,2 & 46,4 \\
\hline $\begin{array}{l}\text { Prob. Preencher Vaga } \\
\text { SI }\left(q_{1}\right)(\%)\end{array}$ & 17,6 & 16,5 & 16,1 & 18,3 & 17,3 & 16,8 & 19,1 & 18,2 & 17,9 \\
\hline
\end{tabular}

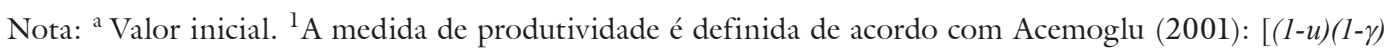
$\left.p_{F}+\gamma(1-u) p_{I}\right]$.

\section{TABELA A.3 - IMPOSTO SOBRE A FOLHA}

\begin{tabular}{|c|c|c|c|c|c|c|c|c|c|}
\hline & \multicolumn{3}{|c|}{$\rho=0,2$} & \multicolumn{3}{|c|}{$\rho=0,3^{\mathrm{a}}$} & \multicolumn{3}{|c|}{$\rho=0,4$} \\
\hline Variáveis & $\pi_{\pi}=0,25$ & $\pi_{\pi}=0,35$ & $\pi_{\pi}=0,45$ & $\pi_{\pi}=0,25$ & $\pi_{\pi}=0,35$ & $\pi_{\pi}=0,45$ & $\pi_{\pi}=0,25$ & $\pi_{\pi}=0,35$ & $\pi_{\pi}=0,45$ \\
\hline Desemprego (\%) & 17,3 & 17,5 & 17,7 & 17,2 & 17,4 & 17,6 & 17,2 & 17,4 & 17,6 \\
\hline Grau de Formal.(\%) & 51,2 & 50,4 & 49,7 & 51,8 & 51,0 & 50,3 & 52,6 & 51,8 & 51,0 \\
\hline Grau de Informal.(\%) & 31,5 & 32,1 & 32,6 & 31,0 & 31,6 & 32,1 & 30,2 & 30,8 & 31,4 \\
\hline Diferencial (\%) & $-12,5$ & $-14,8$ & $-17,0$ & $-10,7$ & $-13,3$ & $-15,6$ & $-8,8$ & $-11,4$ & $-13,9$ \\
\hline Índice de Produto & 1,004 & 1,000 & 0,996 & 1,004 & 1,000 & 0,995 & 1,005 & 1,000 & 0,995 \\
\hline Índice de Produtiv. ${ }^{1}$ & 1,002 & 1,000 & 0,998 & 1,002 & 1,000 & 0,998 & 1,002 & 1,000 & 0,997 \\
\hline $\operatorname{Pr}($ Desemp. $\rightarrow$ EF $)(\%)$ & 44,5 & 43,3 & 42,2 & 45,1 & 43,9 & 42,8 & 45,9 & 44,7 & 43,5 \\
\hline $\operatorname{Pr}($ Desemp. $\rightarrow$ EI) $(\%)$ & 64,0 & 64,3 & 64,5 & 62,8 & 63,3 & 63,6 & 61,5 & 62,1 & 62,5 \\
\hline $\begin{array}{l}\text { Prob. Preencher Vaga } \\
\operatorname{SF}\left(q_{F}\right)(\%)\end{array}$ & 41,6 & 44,3 & 47,0 & 40,2 & 42,8 & 45,4 & 38,7 & 41,2 & 43,8 \\
\hline $\begin{array}{l}\text { Prob. Preencher Vaga } \\
\text { SI }\left(q_{1}\right)(\%)\end{array}$ & 17,8 & 17,6 & 17,4 & 18,6 & 18,3 & 18,0 & 19,5 & 19,1 & 18,8 \\
\hline
\end{tabular}

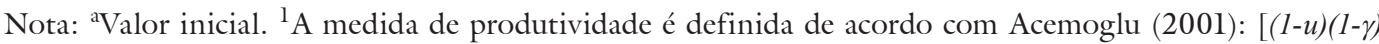
$\left.p_{F}+\gamma(1-u) p_{I}\right]$. 


\section{REFERENCIAS}

ACEMOGLU, D. Good jobs versus bad jobs. Journal of Labor Economics, v. 19, n. 1,2001 .

BARROS, P.B.; CORSEUIL, C.H.; FOGUEL, M.N. Incentivos adversos e a focalização dos programas de proteção ao trabalhador no Brasil. IPEA, 2001 (Texto para Discussão, n. 784).

BOERI, T.; GARIBALDI, P. Shadow sorting. In: PISSARIDES, C.; FRENKEL, J. (eds.). NBER Macroeconomics Annual, MIT Press, 2005.

BOUEV, M. State regulations, job search and wage bargaining: a study in the economics of the informal sector. 2005. (William Davidson Institute Working Paper, n. 764).

CAMARGO, J. M. Fake contracts: justice and labor contracts in Brazil. Brazil Jobs Report, Chapter 6, v. II, World Bank, 2002.

CAVALCANTI, T. V. The effects of government policies on economies with informal markets. Anais do XXIX Encontro da ANPEC, 2001.

CORSEUIL, C. H.; RIBEIRO, E. P.; SANTOS, D. D.; DIAS, R. Criação, destruição e realocação do emprego no Brasil. IPEA, 2002. (Texto para Discussão, n. 855).

CURI, A. Z.; MENEZES-FILHO, N. A. O mercado de trabalho brasileiro é segmentado? Alterações no perfil da informalidade e nos diferenciais de salários nas décadas de 1980 e 1990. Estudos Econômicos, v. 36, n. 4, p. 867-899, out-dez 2006.

DE SOTO, H. The other path. New York: Harper e Row, 1988.

FERNANDES, R.; GREMAUD, A. P.; NARITA, R.T. Estrutura tributária e formalização da economia: simulando diferentes alternativas para o Brasil. Anais do XXIX Encontro da Sociedade Brasileira de Econometria, 2004.

FUGAZZA, M.; JACQUES, J-F. Labor market institutions, taxation and the underground economy. Journal of Public Economics, v. 88, n. 1-2, 2004.

GONZAGA, G. Labor turnover and labor legislation in Brazil. Economía, Journal of the LACEA, v. 4, n. 1, 2003.

HECKMAN, J.; PAGÉS, C. The cost of job security regulation: evidence from Latin American labor markets. Inter-American Development Bank, Research Department, 2000. (Working Paper, n. 430).

KUGLER, A.; KUGLER, M. The labor market effect of payroll taxes in a middle-income country: evidence from Colombia. September, 2003. (CEPR Discussion Paper, $\mathrm{n}$. 4046).

LOAYZA, N. A. The economics of informal sector: a simple model and some empirical evidence from latin america. Carnegie Rochester Series in Public Economics, v. 45 , p. 129-162, 1996. 
MALONEY, W. F. Does informality implies segmentation in urban labor markets? Evidence from sectoral transitions in Mexico. World Bank Economic Review, v. 13 , n. 2, p. 275-302, 1999.

MENEZES-FILHO, N.; MENDES, N.; ALMEIDA, E. O diferencial de salários formal-informal no Brasil: segmentação ou viés de seleção? Revista Brasileira de Economia, v. 58, n. 2, 2004.

MORTENSEN, D.; PISSARIDES, C. Job creation and job destruction in the theory of unemployment. Review of Economic Studies, v. 61, p. 397-415, 1994.

NERI, M. C. Decent work and the informal sector in Brazil. EPGE, Ensaios Econômicos, n. 461, 2002.

PISSARIDES, C. Equilibrium unemployment theory. Oxford: Basil Blackwell, 2000.

REIS, M. C.; ULYSSEA, G. Imposto sobre trabalho e sen impacto nos setores formal e informal. IPEA, 2006. (Texto para Discussão, n. 1.218).

SAINT-PAUL, G. Dual labor markets: a macroeconomic perspective. MIT Press, 1996.

TANNURI-PIANTO, M. E.; PIANTO, D. Informal employment in Brazil - a choice at the top and segmentation at the bottom: a quantile regression approach. Anais do XXIV Encontro Brasileiro de Econometria, v. 2, 2002.

ULYSSEA, G. Informalidade no mercado de trabalho brasileiro: uma resenha da literatura. Revista de Economia Politica, v. 26, n. 4, 2006. 